\title{
POLÍTICAS PÚBLICAS E O FORTALECIMENTO DA AGRICULTURA FAMILIAR NO SERTÃO PARAIBANO
}

\author{
Roberto de Sousa Miranda ${ }^{1}$ \\ Maria da Paz Nascimento dos Santos e Silva ${ }^{2}$ \\ Laiany Tássila Ferreira ${ }^{3}$
}

\begin{abstract}
RESUMO
O objetivo do artigo é analisar políticas de modernização da agricultura, desenvolvimento rural e de fortalecimento da agricultura familiar no Sertão paraibano, a partir do caso da Fazenda São João, que deu origem ao assentamento rural São João II. A metodologia de pesquisa se pautou na consulta de relatórios oficiais, dissertações, livros e artigos que analisaram as políticas públicas responsáveis pela modernização da agricultura no Sertão paraibano; das atas da Associação Comunitária do São João II, da Associação Comunitária dos Agropecuaristas do São João e do Conselho Municipal de Desenvolvimento Agropecuário de Pombal; e na realização de entrevistas semiestruturadas com agricultores familiares. Entre os resultados da pesquisa, é possível ressaltar a rearticulação da agricultura familiar sertaneja, após a implementação das políticas voltadas à criação de assentamentos rurais e de fortalecimento da agricultura familiar, com destaque para a criação de uma agroindústria de processamento de polpas de fruta administrada pelas famílias assentadas.
\end{abstract}

Palavras-chave: Agricultura Familiar, Agroindústria, Modernização Agrícola, Paraíba.

\section{PUBLIC POLICIES AND THE FORTIFICATION OF FAMILY AGRICULTURE IN THE SERTÃO OF PARAÍBA}

\begin{abstract}
The objective of the article is to analyse policies for the modernization of agriculture, rural development and the strengthening of family farming in the Sertão region of Paraíba, starting from the case of Fazenda São João, which gave rise to the rural settlement of São João II. The research methodology was based on the consultation of official reports, dissertations, books and articles that analysed the public policies responsible for the modernization of agriculture in the Sertão Paraíba, and the Acts of the Community Association of São João II, the Community Association of Agropecuaristas do São João and of the Municipal Council of Agricultural Development of Pombal; and semi-structured interviews with family farmers. Among the results of the research, we emphasize the consolidation of the sertaneja family agriculture, after the implementation of policies aimed at the creation of rural settlements and the strengthening of family agriculture, with emphasis on the creation of an agroindustry to process fruit pulp in the settlement.
\end{abstract}

Keywords: Family Agriculture, Agroindustry, Agricultural Modernization, Paraíba.

\section{INTRODUÇÃO}

A antiga Fazenda São João - localizada no município de Pombal, Microrregião de Sousa e Mesorregião do Sertão Paraibano - foi beneficiária, nos anos 1970, de financiamentos para a modernização agrícola. Estes investimentos, liberados via Superintendência do Desenvolvimento do

\footnotetext{
${ }^{1}$ Professor do Programa de Pós-Graduação em Ciências Sociais da Universidade Federal de Campina Grande. E-mail: robertosmiranda@yahoo.com.br

2 Extensionista Social na Empresa de Assistência Técnica e Extensão Rural da Paraíba. E-mail: dapazesilva@yahoo.com.br

3 Mestranda em Engenharia Ambiental na Universidade Federal Rural de Pernambuco. E-mail: laianytassila@hotmail.com
} 
Nordeste (SUDENE), foram utilizados para a construção de infraestrutura necessária para o cultivo do algodão e para a pecuária bovina: cercas, currais, galpões, entre outros. Nos anos 1990, a fazenda se encontrava improdutiva e endividada, cenário que contribuiu para que as famílias meeiras e de arrendatárias criassem a Associação Comunitária do São João II para iniciar a luta pela terra. Em 2001, as famílias compraram a fazenda com um financiamento do Banco da Terra e constituíram o assentamento rural São João II e, no ano de 2004, uma agroindústria para processar, com recursos do Programa de Combate à Pobreza Rural (PCPR).

Tem-se, portanto, um bom exemplo para a análise dos projetos modernizantes no sertão paraibano entre os anos 1970 e 2010, os quais possuem similaridades, como estimular o desenvolvimento mediante o investimento em infraestrutura produtiva, e algumas diferenças, cuja principal é a mudança no perfil dos beneficiários. Nos anos 1970, os principais beneficiários dos projetos e programas de modernização eram médios e grandes proprietários, e, dos anos 1990 em diante, os pequenos proprietários passam a ser contemplados com o Programa Nacional de Fortalecimento da Agricultura Familiar (PRONAF), Crédito Fundiário e PCPR.

Neste sentido, o objetivo do presente artigo é analisar as políticas de desenvolvimento rural, de criação de assentamentos rurais e de fortalecimento da agricultura familiar implementadas no Sertão paraibano, a fim de responder as seguintes questões: Quais os principais impactos das políticas e programas que buscaram modernizar a agricultura sertaneja nos anos 1970? Quais fatores contribuíram para a criação de projetos de assentamentos a partir dos anos 1990? Em que medida as ações governamentais de combate à pobreza e de desenvolvimento rural colaboraram para $o$ fortalecimento da agricultura familiar? A agroindustrialização se constitui a melhor saída econômica para a agricultura familiar? Com essas indagações será possível problematizar as estratégias governamentais adotadas para a região estudada nos últimos 50 anos.

Há uma associação, quase mecânica, da modernização da agricultura à concentração da posse da terra, ao aumento da diferença de renda, à exploração da força de trabalho no campo e ao êxodo rural (Priori et al., 2012; Lima; Silva, 2019). Entretanto, o êxodo rural é anterior à modernização, dado que começou nos anos 1930 (Palmeira, 1989). Apesar de termos bons estudos sobre o tema (Silva et al., 1983; Kageyama, 1990), cabe ainda explorar as consequências locais das iniciativas de modernização agrícola conservadora ${ }^{4}$ que: (a) priorizou a grande propriedade para aumentar a produção e a produtividade; (b) teve resultados diferentes nos estados brasileiros (Silva et al. 1983;

\footnotetext{
${ }^{4}$ Dirigida pelo Estado, o qual sofreu profundas modificações a partir dos anos 1960, que devem ser consideradas: Estatuto da Terra de 1964; criação do Instituto Brasileiro de Reforma Agrária (IBRA) e do Instituto Nacional de Desenvolvimento Agrário (INDA) em 1964; criação do Instituto Nacional de Colonização e Reforma Agrária (INCRA), em 1970, após a fusão do IBRA e do INDA (Palmeira, 1989).
} 
Souza; Lima, 2003); e (c) indicou uma incompatibilidade entre modernização e campesinato $^{5}$ (Bragagnolo; Barros, 2013; Silva; Botelho, 2014).

A modificação dos mecanismos de intervenção no meio rural e o fim dos subsídios financeiros estatais, nos anos de 1990, contribuíram para a reestruturação da agricultura no Nordeste (Piraux; Miranda, 2010; Nunes; Schneider, 2013). Um dos marcos dessa transformação foi a criação do PRONAF, em 1996, que foi sendo reestruturado, desde então, para se adequar à realidade da brasileira, e novas linhas de crédito foram sendo criados, a exemplo da linha de crédito para a agroindústria familiar (Wesz Júnior, 2010). Essas mudanças colaboraram para a diversificação das atividades produtivas e econômicas da agricultura familiar (Pelegrini; Gazolla, 2009; Mattei, 2014).

No Brasil, a categoria agricultor familiar passou a ser utilizada pelos pesquisadores e representantes dos trabalhadores rurais, nos anos 1990 (Neves, 2007; Picolotto, 2014). A sua conceituação não é consensual, pode-se dizer que há duas visões dominantes: (a) uma quantitativa, que toma como base a predominância do trabalho familiar em relação ao trabalho contratado, e o tamanho do estabelecimento agropecuário de no máximo quatro vezes o módulo fiscal (Buainain, 2007); e (b) uma qualitativa, que analisa os aspectos familiares da agricultura familiar para poder defini-la, ressaltando a cultura local, a organização social e as estratégias produtivas e econômicas adotadas (Neves, 2007; Carneiro, 2008).

Agricultor familiar, para o Estado, é aquele que possui área inferior a quatro módulos fiscais, utiliza predominantemente mão de obra familiar nas atividades econômicas do estabelecimento e que a renda familiar está vinculada ao próprio estabelecimento. Além disso, o Estado também considera como agricultores familiares: os silvicultores, os aquicultores, os extrativistas, os pescadores, os indígenas, os quilombolas e os assentados (Brasil, 2006), atores que outrora eram considerados pelas suas especificidades (lavradores, meeiros, arrendatários, trabalhadores rurais, entre outros), foram incorporados pela definição ampla construída pelo Estado.

Refletir criticamente sobre as políticas de desenvolvimento rural nos anos 1970 e 1980 e o fortalecimento da agricultura familiar a partir dos anos 1990, no Sertão paraibano, exigiu a consulta: de relatórios de avaliação do Programa de Desenvolvimento de Áreas Integradas do Nordeste (POLONORDESTE) e do Programa Especial de Apoio ao Desenvolvimento da Região Semiárida (PROJETO SERTANEJO); de dissertações produzidas no Mestrado em Sociologia Rural da Universidade Federal da Paraíba ${ }^{6}$; e de livros e artigos que trataram destas questões.

\footnotetext{
${ }^{5}$ Em algumas partes do texto serão utilizados os conceitos de pequeno produtor, meeiros e assentados porque, no momento em que os atores publicaram seus trabalhos, o conceito de agricultura familiar não existia ou não era utilizada.

${ }^{6}$ O Mestrado em Sociologia Rural deixou de existir com a criação do Programa de Pós-Graduação em Sociologia em 1999, com duas bases, uma em João Pessoa e outra em Campina Grande. Após a criação da Universidade Federal de Campina Grande, em 9 de abri de 2002, em virtude do desmembramento da Universidade Federal da Paraíba, foi criado o Programa de Pós-Graduação em Ciências Sociais, em 2006, que se tornou o herdeiro da produção acadêmica do Mestrado em Sociologia Rural.
} 
A apreensão dos processos de criação do assentamento São João II se deu a partir da consulta das atas da Associação Comunitária do São João II, da Associação Comunitária dos Agropecuaristas do São João e do Conselho Municipal de Desenvolvimento Agropecuário de Pombal; assim como da realização de 13 entrevistas semiestruturadas com as famílias assentadas entre o ano de 2013 e o primeiro semestre de 2017. A escolha dos entrevistados priorizou os agricultores familiares que atuam na agroindústria desde a sua criação, de modo que os agentes públicos envolvidos e as políticas públicas e programas governamentais que possibilitaram e que entravaram o fortalecimento e a consolidação da agricultura familiar fossem compreendidos.

$\mathrm{O}$ artigo está organizado em quarto partes, que revelam as modificações dos programas e políticas públicas para a agricultura familiar no Brasil: (a) resgate das políticas e programas governamentais destinados à modernização das atividades agropecuárias, a partir dos anos 1970; (b) a reestruturação fundiária e o fortalecimento da agricultura familiar, a partir dos anos 1990, no Sertão paraibano; (c) processo de criação do assentamento rural São João II; e (d) a análise do processo de criação da Agroindústria de Polpa de Frutas Fonte do Sabor.

\section{A MODERNIZAÇÃO DA AGRICULTURA NO SERTÃO PARAIBANO}

A formação do território paraibano teve início com a fundação da cidade de Nossa Senhora das Neves - hoje, João Pessoa -, no século XVI, e foi pautada na expropriação da terra e sujeição de grupos indígenas. $\mathrm{O}$ avanço da colonização dividiu o território paraibano em duas áreas: (a) na Zona da Mata, onde se iniciou a colonização, desenvolveu-se a produção de Cana-de-açúcar; e (b) no Agreste e no Sertão, responsáveis pela criação de bovinos e pela produção de alimentos destinados à população local e aos habitantes da Zona da Mata (Moreira; Targino, 1997).

A atividade pecuária foi, durante um tempo expressivo, ultra extensiva e rudimentar. Até os anos 1950 os rebanhos eram criados soltos e as áreas de cultivo eram cercadas. Na década de 1970, programas governamentais de modernização da agricultura brasileira ofertavam crédito subsidiado para cercamento de terras, melhoria das pastagens e dos rebanhos bovinos, além de custeio do processo produtivo. A modernização da pecuária paraibana inviabilizou a manutenção do pequeno criatório porque o simples fato de possuir gado não dava mais direito à solta (Sousa, 1994) e os pequenos criadores não tiveram acesso aos programas modernizantes.

A expansão da pecuária bovina na Paraíba, entre 1970-1975, refletiu o fenômeno da pecuarização dos latifúndios do Nordeste, no momento em que as condições políticas e econômicas forneceram as bases para a sua modernização. Um dos principais programas federais para subsidiar a atividade pecuária foi o Programa de Redistribuição de Terras e Estímulo à Agroindústria do Norte e Nordeste (PROTERRA), criado em 1971, que estimulou a aquisição de terras e um novo movimento de concentração fundiária. 
Para Fernandes (1995, p. 28-29), somente nos “(...) anos 70 [1970], surgem no País as primeiras experiências voltadas para a pequena e média produção, através dos Programas de Desenvolvimento Rural Integrado (PARI's)". Os principais programas foram: POLONORDESTE, criado pelo Decreto n. 74.794, de 30 de outubro de 1974; o PROJETO SERTANEJO, criado pelo Decreto n. 78.299, de 23 de agosto de 1976; e o Programa de Desenvolvimento da Região Nordeste (PROJETO NORDESTE), criado pelo Decreto n. 91.179, de 1 de abril de 1985.

O POLONORDESTE foi o primeiro programa implementado após a moderna fase de irrigação pública do Nordeste, para promover o desenvolvimento e a modernização das atividades produtivas em áreas prioritárias: de Vale Úmidos, bacias hidrográficas do Rio São Francisco e do Rio Parnaíba, e os vales de Jaguaribe, Piranhas-Açu e Ceará-Mirim; de Serras Úmidas, do Ibiapaba, de Baturité, do Araripe, do Martins, do Brejo, do Teixeira e do Triunfo; da Agricultura Seca, Sertão Cearense e Chapada Diamantina; dos Tabuleiros Costeiros, do Rio Grande do Norte ao Sul da Bahia; e da Pré-Amazônia, o Oeste do Maranhão (BNB, 1985).

Na Paraíba, quatro áreas prioritárias foram contempladas pelo POLONORDESTE: Sudoeste Paraibano, Seridó Paraibano, Vale do Piranhas e Vale do Rio do Peixe. Entre 1975 e 1982, 21.753 agricultores foram atendidos nas quatro áreas. Dentre as metas previstas, a regularização e reestruturação fundiária foi a que teve o pior desempenho em todos os Estados beneficiados. Foram adquiridos 127.877 ha, $61,9 \%$ da meta, e redistribuídos 45.293 ha, 16,4\% da meta, beneficiando apenas 25,3\% do número de agricultores previstos (BNB, 1985). Demonstra-se, assim, a contribuição do programa para a manutenção da concentração fundiária, a modernização do latifúndio e para o reforço da marginalização dos pequenos proprietários e dos trabalhadores rurais sem terra.

O PROJETO SERTANEJO foi instituído com a finalidade de fortalecer a economia das unidades de produção agropecuárias, especialmente as pequenas e médias, do Semiárido nordestino para torná-las mais resistentes aos efeitos das secas, mediante a criação de núcleos de prestação de serviços e de assistência técnica ${ }^{7}$. Estes núcleos foram denominados Núcleos Sertanejos, situados nos projetos de irrigação do Departamento Nacional de Obras Contra a Seca (DNOCS) ${ }^{8}$ ou em áreas contempladas pelo POLONORDESTE (BNB, 1985).

\footnotetext{
${ }^{7}$ As linhas de ação eram: formação de reservas de água, intensificação da produção irrigada, economia no uso da água, fomento à agricultura seca, intensificação da produção pecuária, conservação e melhoria do solo, reorganização da estrutura fundiária, prestação de assistência técnica, prestação de assistência financeira e aperfeiçoamento do sistema de comercialização de abastecimento (BNB, 1985).

${ }^{8} \mathrm{Na}$ Paraíba, existem três perímetros públicos de irrigação coordenados pelo DNOCS: o Perímetro Irrigado Engenheiro Arcoverde, localizado no município de Condado, no Sertão Paraibano, a sua implantação se iniciou em 1971 e conclusão ocorreu em 1973, possui uma área irrigável de 278,65 ha, com 54 agricultores familiares; o Perímetro Irrigado São Gonçalo, localizado no município de Sousa, no Sertão Paraibano, a sua implantação se iniciou no ano de 1972, enquanto os serviços de administração, operação e manutenção da infraestrutura de uso comum foram implementados a partir de 1973, possui uma a área irrigável de 3.045,63 ha, com 452 agricultores familiares; o Perímetro Irrigado Sumé, localizado no município de mesmo nome, no Agreste Paraibano, teve a implantação iniciada no ano de 1970 e sua conclusão ocorreu em 1976, possui uma área irrigável de 273 ha, com 57 agricultores familiares. (DNOCS, 2013).
} 
A área de atuação do PROJETO SERTANEJO compreendia, prioritariamente, os Sertões do Piauí, do Ceará, do Rio Grande do Norte, da Paraíba, de Alagoas, de Sergipe, de Pernambuco e da Bahia. Os beneficiários do projeto estavam divididos em quatro estratos: (a) trabalhadores sem-terra e assalariados; (b) pequenos proprietários; (c) médios proprietários, com áreas de até 500 ha; e (d) proprietários com áreas acima de 500 ha. Na Paraíba, entre 1977 e 1981, havia 15 Núcleos Sertanejos, que beneficiaram 1.221 proprietários do segundo estrato e 800 do terceiro estrato (BNB, 1985).

Em nenhum dos Estados contemplados pelo PROJETO SERTANEJO houve projetos contratados para os trabalhadores sem-terra e assalariados, beneficiários do estrato 1. As avaliações do BNB (1985) ressaltam que a totalidade das ações desenvolvidas neste projeto não produziram resultados satisfatórios frente às metas propostas. Embora o projeto tivesse suas ações voltadas para os produtores rurais mais carentes, os sem-terra e assalariados foram marginalizados, enquanto $62 \%$ das operações de crédito foram para produtores com mais de 100 ha.

Avaliações posteriores dos dois programas revelaram a existência de uma preocupação acentuada com o desenvolvimento econômico do Nordeste em detrimento das atividades de subsistência no meio rural e a exclusão das condições sociais e políticas regionais do debate (Ramalho, 1992). Em termos administrativos, todos os programas eram similares em relação ao crédito: verbas incompletas e/ou atrasadas. Além disso, as obras de infraestrutura, por si só, não resolviam os problemas e necessidades dos pequenos produtores (Fernandes, 1995).

A constatação do fracasso desses programas gerou inquietações no governo e nas agências de fomento. O Banco Mundial, em 1981, questionou a superposição de ações do Estado na região Nordeste e sugeriu a implantação de um único programa de desenvolvimento rural a ser financiado (Chaloult, 1985). Para atender às recomendações, foi criado o Projeto Nordeste, sob a égide do Banco Mundial, pautado na defesa e no planejamento participativo, e na melhoria de vida no meio rural.

As diretrizes dos programas governamentais voltados para o Nordeste enfatizavam a participação dos pequenos produtores nos processos de tomada de decisão. O que não ocorria na prática, já que os beneficiários não tinham oportunidade real de se manifestar. Os programas acabaram servindo como moeda de troca, na negociação e defesa de interesses do Governo Federal e dos Estados ${ }^{9}$, cujos grupos dominantes influenciavam decisivamente em subprojetos, preservando e reforçando seus interesses. Além disso, os poderes municipais interferiram pouco nos programas.

\section{AGRICULTURA FAMILIAR NO SERTÃO PARAIBANO}

O fim dos subsídios estatais para a grande agricultura, no início dos anos 1990, e a formulação de políticas públicas para os pequenos proprietários, na segunda metade dos anos 1990 e nos anos

\footnotetext{
${ }^{9}$ A influência do Poder Federal Executivo Nacional, base das origens, é dividido por escala, entre a SUDENE e os Estados, e há a tendência de reforçar progressivamente os Estados (Fernandes, 1995).
} 
2000, contribuíram para o fortalecimento da agricultura familiar no Sertão paraibano, e muitas terras que formavam grandes fazendas foram desapropriadas para a criação de assentamentos rurais (Piraux; Miranda, 2010). Em 1987, foram criados os primeiros assentamentos no Sertão paraibano, beneficiando 38 famílias em 2 assentamentos que totalizaram 684,8037 ha. Nos anos 1990, os números são mais expressivos, 621 famílias foram assentadas em 12 assentamentos, que totalizaram 13.569,5145 ha. Entre 2000 e 2017, 1.927 famílias foram assentadas em 53 assentamentos que totalizaram 58.272,8407 ha (Tabela 1$)$.

Tabela 1 - Número de assentamentos criados, de famílias assentadas e da área no Sertão paraibano

\begin{tabular}{|c|c|c|c|}
\hline ANO & $\begin{array}{c}\text { ASSENTAMENTOS } \\
\text { CRIADOS }\end{array}$ & $\begin{array}{c}\text { FAMÍLIAS } \\
\text { ASSENTADAS }\end{array}$ & $\begin{array}{c}\text { ÁREA } \\
(\text { EM HECTARES) } \\
\end{array}$ \\
\hline 1987 & 2 & 38 & 684,8037 \\
\hline 1996 & 2 & 78 & 257,0437 \\
\hline 1997 & 6 & 379 & $9.469,6325$ \\
\hline 1998 & 2 & 76 & 1445,6 \\
\hline 1999 & 2 & 88 & $2.397,2383$ \\
\hline 2000 & 2 & 29 & 753,979 \\
\hline 2001 & 6 & 201 & $6.819,6549$ \\
\hline 2002 & 1 & 28 & 803 \\
\hline 2003 & 5 & 178 & $7.748,615$ \\
\hline 2004 & 7 & 276 & 9424,72 \\
\hline 2005 & 3 & 88 & $1.639,0526$ \\
\hline 2006 & 2 & 149 & 866,1814 \\
\hline 2007 & 4 & 188 & $5.600,9842$ \\
\hline 2008 & 2 & 43 & $3.372,2024$ \\
\hline 2009 & 5 & 157 & $5.419,7247$ \\
\hline 2010 & 4 & 121 & $5.338,1112$ \\
\hline 2011 & 4 & 231 & $4.185,9279$ \\
\hline 2012 & 5 & 101 & $4.494,8783$ \\
\hline 2013 & 1 & 12 & 592,6325 \\
\hline 2014 & 1 & 15 & 771,7266 \\
\hline 2015 & - & - & - \\
\hline 2016 & - & - & - \\
\hline 2017 & 1 & 110 & 441,45 \\
\hline TOTAL & 67 & 2.586 & $72.527,1589$ \\
\hline
\end{tabular}

Fonte: INCRA, 2017.

Em meados de 1996, começaram a ser implementados, no Brasil, Programas de Reforma Agrária de Mercado, na tentativa de conter a pressão social das lutas históricas pelo acesso à terra, a 
partir de dois projetos: (a) um desenvolvido no Estado do Ceará, denominado Reforma Agrária Solidária e o (b) outro projeto, denominado Cédula da Terra, implantado entre 1997 e 2002, em cinco Estados no Nordeste, incluindo o Ceará, sendo considerado um projeto piloto de reforma agrária e alívio da pobreza rural (Victor; Sauer, 2002; Sauer; Pereira, 2006).

Os principais objetivos do Programa Cédula da Terra eram: (a) reduzir a pobreza rural, através do aumento de renda e da qualidade de vida familiar; (b) aumentar a produtividade agrícola familiar; (c) testar o modelo de reforma agrária de mercado, para que uma alternativa da posse de terra com interesse social, que não fosse o modelo tradicional de reforma agrária, contribuísse para a desconcentração fundiária (Buainain et al., 1999). Embora o governo não tenha assumido, a Reforma Agrária de Mercado procurava desarticular os movimentos sociais rurais, principalmente o Movimento dos Trabalhadores Rurais Sem Terra (MST).

Duas novas experiências de Reforma Agrária de Mercado foram implantadas entre 1998 e 2003: o Banco da Terra e o Programa Nacional de Crédito Fundiário (PNCF). O Banco da Terra era um programa de reordenamento fundiário e criação de assentamentos rurais. No governo Lula, o programa foi reformulado e o nome foi modificado para Programa de Consolidação de Agricultura Familiar (PCAF), que implementou o Crédito Fundiário e criou uma linha de crédito para jovens agricultores, Nossa Primeira Terra. Todos esses programas são regidos pelo PNCF, responsável pela gestão do Fundo de Terras e Programas de Reforma Agrária (Brasil, 2003; Galindo et al., 2015).

Para o governo federal, o PNCF deveria ser um instrumento complementar e de apoio à reforma agrária, criado para aperfeiçoar os projetos anteriores com ampla participação dos movimentos sociais organizados, com destaque para a Confederação Nacional dos Trabalhadores na Agricultura (CONTAG), que procurava criar empregos no campo, diminuir o êxodo rural, democratizar o acesso à terra e às de linhas de crédito para compra de imóveis e de investimentos em infraestrutura básica e produtiva (Brasil, 2003).

\section{CRIAÇÃO DO ASSENTAMENTO RURAL SÃO JOÃO II}

A história do assentamento São João II remete ao início dos anos 1940, quando a família Calixta se instala na Fazenda São João, do casal Hamlet de Assis Arnaud e Geni de Assis Arnaud, para trabalhar como meeiros no cultivo do algodão, do milho e do fumo, e na pecuária bovina atividades impulsionadas pelos créditos do POLONORDESTE e do PROJETO SERTANEJO, nos anos 1970. Com o fim dos programas e dos subsídios governamentais para a pecuária de corte no início da década de 1990, os meeiros passaram a cultivar exclusivamente batata doce, feijão, macaxeira e a criar animais de pequeno porte. Mesmo com o falecimento do senhor Hamlet de Assis Arnaud, em setembro de 1996, as herdeiras Geni de Assis Arnaud (viúva), Glória Arnaud e Vamberta Arnaud (filhas) mantiveram o sistema de meação. 
Nos anos 1990, os pequenos produtores rurais passaram a se organizar formalmente em sindicatos e associações, para pleitearem reforma agrária, crédito e assistência técnica. É neste cenário que, no dia 8 de janeiro de 1995, os meeiros da Fazenda São João criam a Associação Comunitária do São João II (Associação Comunitária do São João, 1995, p. 1), a qual passou a integrar o Conselho Municipal de Desenvolvimento Agropecuário de Pombal, criado para operacionalizar o PRONAF ${ }^{10}$. Na reunião do conselho do dia 14 de novembro de 2000, os meeiros foram informados sobre o Banco da Terra (Conselho Municipal de Desenvolvimento Agropecuário de Pombal, 2001).

Decididos a comprar a Fazenda São João, com um financiamento do Banco da Terra (parcelado em 20 anos e com 36 meses de carência para o pagamento da primeira parcela), as 15 famílias de meeiros descendentes da família Calixta, a quarta geração, organizaram toda a documentação exigida e, no dia 17 de dezembro de 2001, adquiriram os 266 ha da Fazenda e criaram o assentamento rural São João II (Figura 1), localizado às margens do Rio Piranhas. As 15 famílias foram distribuídas em lotes individuais de 17 ha, e passaram de meeiros a pequenos proprietários, organizando suas atividades produtivas nos moldes da agricultura familiar. (Silva, 2009).

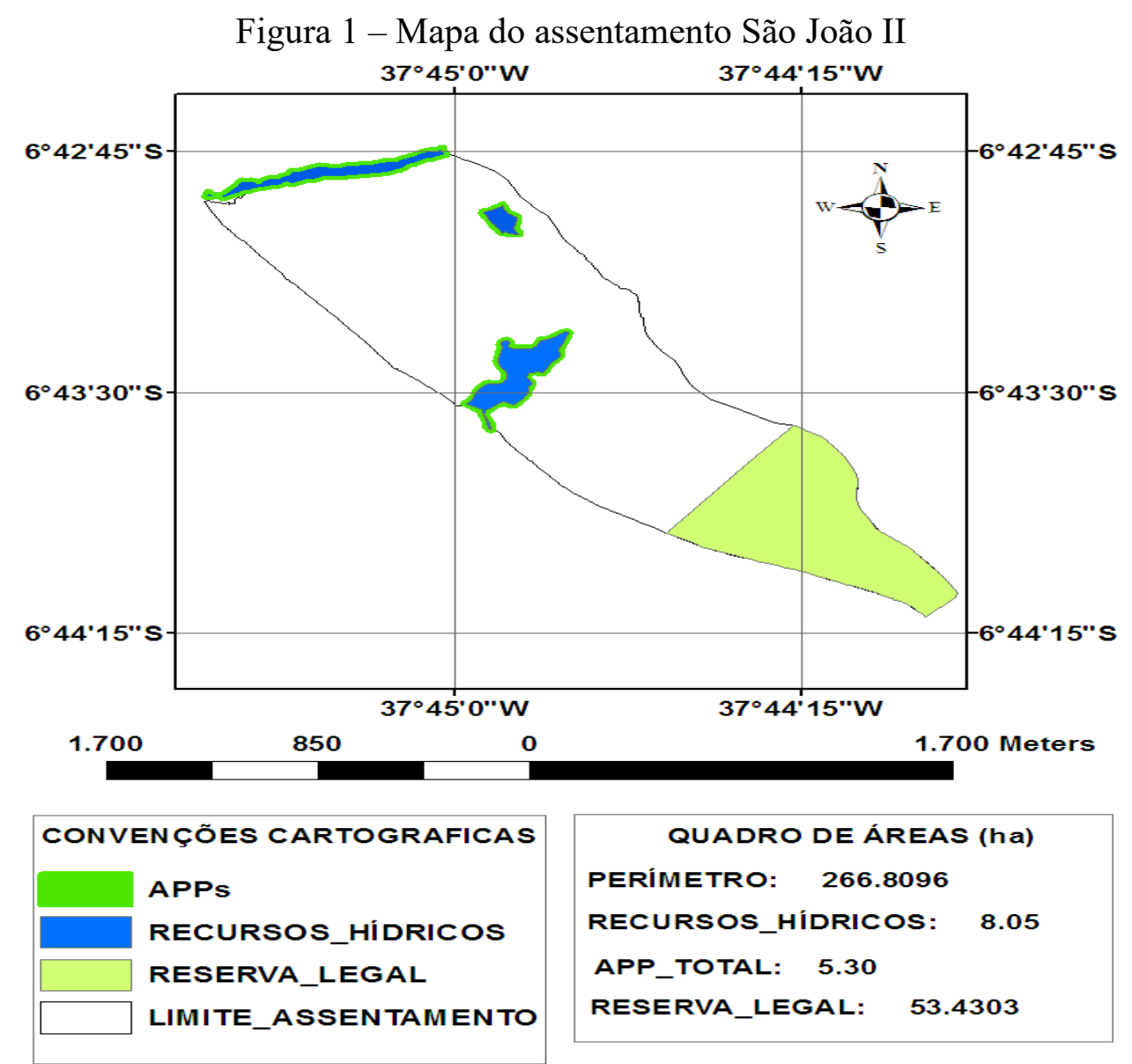

Fonte: Miranda e Silva (2017).

\footnotetext{
${ }^{10}$ Os municípios brasileiros tiveram que criar conselhos com 50\% de representantes de agricultores familiares para deliberar sobre as ações do PRONAF, especialmente as voltadas para a Infraestrutura (Moura, 2007).
} 
Como a Associação Comunitária do São João II possuía agricultores familiares que não eram assentados no seu quadro de sócios, foi necessária a criação de uma nova associação para que as famílias do assentamento São João II tivessem uma instituição formal própria. No dia 5 de fevereiro de 2003, foi criada a Associação Comunitária dos Agropecuaristas do São João, e, de acordo com a ata de fundação, estiveram presentes na assembleia 15 agricultores familiares do assentamento e a equipe técnica da Empresa de Assistência Técnica e Extensão Rural da Paraíba (EMATER/PB) (Silva, 2009). O nome da associação representa a incorporação de um discurso modernizante, que não passa pela denominação de assentados ou pequenos produtores, mas agropecuaristas, termo comumente relacionado a médio e grandes produtores.

O assentamento São João II possui uma Área de Reserva Legal de 53,4303 ha, de onde as famílias extraem lenha para o uso doméstico (árvores mortas, na maioria dos casos), estacas e mourões para a fabricação de cercas, e colocam animais para pastar (muito embora a legislação ambiental brasileira vigente não permita); e cinco reservatórios de água entre açudes e tanques, além de ser banhado pelo Rio Piranhas. Os reservatórios fornecem água para o consumo animal e para irrigação por microaspersão de hortaliças e frutíferas. A água utilizada para o consumo humano é fornecida pelo rio, sendo tratada nas residências com uso de hipoclorito de sódio, distribuído pelo agente de saúde (Figura 1).

A economia do assentamento é baseada no cultivo de milho, batata doce, mandioca, feijão e tubérculos, para o consumo próprio e para a comercialização através dos programas de compra direta; na produção de banana irrigada, que é comercializada na forma in natura; na venda de polpa de frutas: acerola, goiaba, manga e caju, que são beneficiadas na agroindústria de polpa de frutas; e na da produção bovina, caprina, ovina e avícola (ovos e galinhas).

Todos os agricultores familiares do São João II acessaram o PRONAF A, em 2007, específíco para assentados da reforma agrária, mas, dos 15 agricultores familiares do assentamento, 12 já passaram para a linha de crédito PRONAF C, o que, segundo eles, dificultou a capacidade de pagamento dos empréstimos já adquiridos:

(...) o empréstimo no Banco do Nordeste (PRONAF A) melhorou nossa vida (...) compramos animais, equipamentos de irrigação, implantamos nossas culturas (...), mas nos endividamos no Banco do Brasil (PRONAF C), o que prejudicou nossos pagamentos. (Entrevista com Manoel).

O grau de inadimplência foi bastante elevado, devido à mudança de categoria do PRONAF e à falta de experiência com o cultivo de goiaba. Essas dificuldades não impediram que, em 2007, as famílias passassem a vender parte da produção para a Companhia Nacional de Abastecimento (CONAB), a partir do programa de Compra Direta (Associação Comunitária dos Agropecuaristas do São João, 2007, p. 15). Os assentados entrevistados destacaram que o programa foi de grande valia: 
“já está com três anos que eu trabalho lá, quando eu comecei já (...) quando eu comecei a participar, não era individual, de porta em porta como antes, já tinham as compras certas" (Entrevista com Antônio).

O principal problema vivido pelos agricultores familiares do São João II, até o final de 2016, estava relacionado ao não pagamento das parcelas de financiamento da terra. Terminada a carência de 36 meses, a primeira parcela do financiamento coletivo não foi paga pelos agricultores familiares. Em virtude da inadimplência, o BNB encaminhava os nomes dos agricultores familiares titulares dos lotes para o Cadastro Informativo de Créditos Não Quitados do Setor Público Federal (CADIN), o que os impedia de acessarem o PRONAF. Sem acesso a crédito, as dificuldades para o desenvolvimento de atividades agropecuárias se agravavam.

\section{IMPLEMENTAÇÃO DA AGROINDÚSTRIA DE PROCESSAMENTO DE FRUTAS}

A agroindústria do assentamento São João II foi implementada, em 2004, pelo Projeto Cooperar do Governo do Estado da Paraíba, com recursos do PCPR, em parceria com a Associação Comunitária dos Agropecuaristas do São João. O nome escolhido para a agroindústria foi Agropecuária Fonte de Sabor. A capacitação dos agricultores familiares para o processamento de polpa de frutas foi realizada pelo Serviço Brasileiro de Apoio às Micro e Pequenas Empresas (SEBRAE) (Garcia, 2013).

De acordo com o Livro de Atas e as entrevistas, verificou-se que a ideia para criação da agroindústria de beneficiamento de frutas partiu do chefe de gabinete do Instituto de Terras e Planejamento Agrícola da Paraíba (INTERPA), o senhor José Alves, que, em reunião realizada no dia 26 de fevereiro 2004, na casa sede do assentamento, apresentou a possibilidade de construção da edificação para que se pudesse garantir o processamento da safra de goiaba do sítio Jutubarana, município de Lagoa, que iria ser colhida em julho do referido ano (Associação Comunitária dos Agropecuaristas do São João, 2004, p. 6).

\footnotetext{
Foi assim, nós estávamos aqui e, nessa época, o presidente do INTERPA era Neto Paixão, e Neto veio uma reunião aqui e, quando chegou, perguntou se alguém queria doar um terreno para fazer uma agroindústria ou qualquer coisa que tivesse renda, não é? Aí eu disse que minha parte eu iria doar, aí a gente se reuniu. Da Paz mandou chamar os meninos e se combinou, porque uns queriam fábrica de doce, outros queriam queijeiras e depois outros disseram... as polpas de fruta e chegamos à um consenso que todo mundo aceitou as polpas de fruta, em 2006. (Entrevista com Dona Diá).
}

No dia 26 de agosto de 2004, na casa sede do assentamento, houve uma assembleia para a aprovação da construção do edifício em que iria funcionar a agroindústria. Foi reservada uma área de $892 \mathrm{~m}^{2}$, que seria doada, com escritura pública, para a Associação, decisão aprovada por unanimidade (Associação Comunitária dos Agropecuaristas do São João, 2004, p. 8). Para dar andamento ao 
projeto, no dia 16 de janeiro de 2005, houve uma assembleia para deliberar sobre a necessidade de uma capacitação para os agricultores familiares aprenderem a manusear os equipamentos comprados e, assim, colocá-los para funcionar (Associação Comunitária dos Agropecuaristas do São João, 2005, p. 9).

Em maio de 2005, a presidente da associação, Maria da Paz Nascimento dos Santos, em assembleia, abordou o tema das pessoas que iriam trabalhar na agroindústria de beneficiamento de polpa de frutas, sendo elas: Manoel José dos Santos, Renio Robson da Silva Sousa, Maria Aucilene do Nascimento Lima, Avanir do Nascimento Santos, Maria da Paz Nascimento dos Santos e Maria Gorete Marcolino da Silva. Vale salientar ainda que a associação iria receber uma biblioteca do Banco do Brasil, que seria colocada no escritório da agroindústria (Associação Comunitária dos Agropecuaristas do São João, 2005, p. 10).

\begin{abstract}
Inicialmente, começou com quatro pessoas, alguns não acreditaram. Ficamos nós quatro, a gente começou a trabalhar. No início, vendíamos nas casas, a gente fazia, colocava no isopor e levava no carro do leite, chegávamos à rua e ficávamos vendendo nas quartas e nos sábados, de casa em casa. Toda semana que passava ia só entregar, com o passar do tempo [...] começo eu, Da Paz, Cilene e Gorete. Aí foi aumentando e eles viram que dava certo, aí, quando surgiu o compra direta, começamos a colocar no Programa Compra Direta que todo mundo tinha, aí ficou os homens. (Entrevista com Dona Diá).
\end{abstract}

Por ser a única agroindústria de beneficiamento de polpa de fruta gerida por agricultores familiares no município de Pombal e tida pelos gestores públicos como um modelo, muitas propostas para a elaboração de projetos de aprimoramento do processo produtivo eram oferecidas. No dia 9 de fevereiro de 2010, o senhor Regildo Costa (Engenharia e Serviço) e a senhora Kenia Cristina G. dos Santos (Consultoria e Projetos) apresentaram aos produtores um edital que iria trabalhar nos projetos produtivos direcionados ao assentamento, que tinham como objetivo a geração de emprego e renda, além de fortalecer o associativismo e cooperativismo rural.

Os projetos apresentados pelos consultores seriam desenvolvidos em parceria com o governo federal e estadual. Cada projeto poderia liberar até R $\$ 600$ mil e teria assistência técnica de 1 ano e 8 meses, após sua implantação. Diante da proposta, as famílias priorizaram a ampliação da agroindústria, com melhoria nas instalações, maquinário e vestimentas, além da implantação de 1 ha de fruticultura irrigada em cada lote dos associados, para o fornecimento de matéria-prima (Associação Comunitária dos Agropecuaristas do São João, 2010, p. 19).

No dia 23 de julho de 2011, foi apresentado aos agricultores familiares o Programa Estadual de Apoio ao Empreendedorismo, que apoiava e fomentava núcleos de indução produtiva. O programa disponibilizava um financiamento no valor de R $\$ 36$ mil, com juros de 0,9\% ao mês, dividido em 60 parcelas, com uma carência de 6 meses, distribuídos da seguinte forma: durante a carência, seriam pagos os juros no valor de $\mathrm{R} \$ 333$, e, após a carência, teriam 54 parcelas no valor de $\mathrm{R} \$ 1.111$, que seria utilizado para a aquisição de 2 freezers, 1 balança digital, 1 máquina de envase e selagem 
automática e para capital de giro (Associação Comunitária dos Agropecuaristas do São João, 2011, p. 21).

Como nem a proposta apresentada pelos consultores, nem o Programa Empreender deram certo, houve, no dia 29 de janeiro de 2012, uma assembleia para priorizar um subprojeto do Projeto Cooperar. Os agricultores familiares decidiram ampliar a agroindústria com recursos próprios, a partir da aquisição de: 1 câmara fria, 1 máquina de envase e de selagem automática, materiais para cercar a agroindústria, forro de PVC, climatizador, cursos de capacitação em gestão e oficina de gerenciamento, o Manual de Boas Práticas de Fabricação (BPF), a Anotação de Responsabilidade Técnica (ART) e o requerimento solicitando o registro do estabelecimento junto ao Ministério da Agricultura Pecuária e Abastecimento (MAPA) (Associação Comunitária dos Agropecuaristas do São João, 2012, p. 22).

O que estava precisando eram os equipamentos, máquinas de selagem... porque era tudo manual. Agora estamos comprando pelo Cooperar e vem tudo automatizado, estamos lutando. Está para sair, e se sair é uma grande vantagem para gente, era o que mais estava dando trabalho, porque, por mais que a gente tenha higiene na fábrica, sempre aparece alguma coisa, e, nessa máquina de envase a gente quase não tem contato. (Entrevista com Antônio).

O processamento de polpa de frutas congeladas inclui uma sequência de etapas que deve ser seguida a fim de se obterem produtos dentro dos padrões de segurança do alimento estabelecidos pelo Ministério da Saúde (MS) e pelo MAPA, que emitiu o registro de funcionamento em 2010. Os produtores da agroindústria destacam, sempre que podem, o papel da Universidade Federal de Campina Grande (UFCG) e dos projetos desenvolvidos lá:

\footnotetext{
Melhorou bastante. A agroindústria melhorou bastante, e depois que o pessoal da Universidade (...) e os professores começaram a vir dar cursos aqui, agora faço como diz a história: foi fatal! Aí foi que contribuiu bastante, porque aumentou mais, pois a gente ainda não estava vendendo para a merenda escolar, $\mathrm{e}$, com a vinda de vocês mais os professores, $\mathrm{o}$ pessoal começou a saber. Depois também desse prêmio que Preta [Maria da Paz, presidente da associação] ganhou do SEBRAE, [Prêmio SEBRAE Mulher de Negócio] também contribuiu bastante, porque aumentou essas cidades fora que não tínhamos, a gente não estava vendendo, começaram a procurar. E pessoas mesmo nas casas, hoje mesmo tem muitas pessoas que estão atrás (...). Em restaurantes também estão atrás já, é porque estamos sem a máquina, aí não adianta. Nem tem a máquina, nem tem a câmara fria, e não dá, porque só os freezers são poucos. (Entrevista com Dona Dia).
}

Como as frutas produzidas no assentamento não são suficientes para garantir a produção de polpa, os agricultores familiares compram coletivamente algumas frutas, a exemplo da graviola, uva e umbu, etc., para complementar a produção de polpas de fruta da agroindústria, adquirida pela Prefeitura Municipal de Pombal, através do Compra Direta da Agricultura Familiar. O valor pago, depois de cobertos os gastos produtivos, é dividido igualmente entre todos os agricultores familiares que participaram da produção. 
A partir de 2013, a agroindústria priorizou a fabricação de cinco tipos de polpa: manga, goiaba, acerola, maracujá e caju. A escolha se deve: (a) à alta produtividade que essas frutas possibilitam, com exceção do maracujá; (b) à facilidade de acesso às referidas frutas na região e Estados vizinhos; e (c) à necessidade de atender às exigências do Programa Dinheiro Direto na Escola, especialmente o artigo 12 da Lei $n^{\circ} 11.947$, de 16 de junho de 2009, que trata da elaboração dos cardápios da alimentação e ressalta que as referências nutricionais e os hábitos alimentares locais devem ser respeitados (Brasil, 2009).

A reestruturação do processo produtivo da agroindústria, iniciada no final de 2012, apresentou bons resultados. Entre 2013 e 2016, a produção cresceu (Gráfico 1), com destaque para a polpa de goiaba, porque a fruta é produzida no assentamento e é de fácil acesso na região. Contudo, em 2016 e 2017, a produção teve uma redução, explicada pela seca que atingia o Nordeste desde 2012 e vem se agravando nos dois últimos anos e pelo aumento do preço das frutas utilizadas para a fabricação da polpa, em virtude da diminuição da oferta das mesmas.

Gráfico 1 - Produção anual de polpa de fruta da agroindústria entre 2013 e 2017 (em Kg)

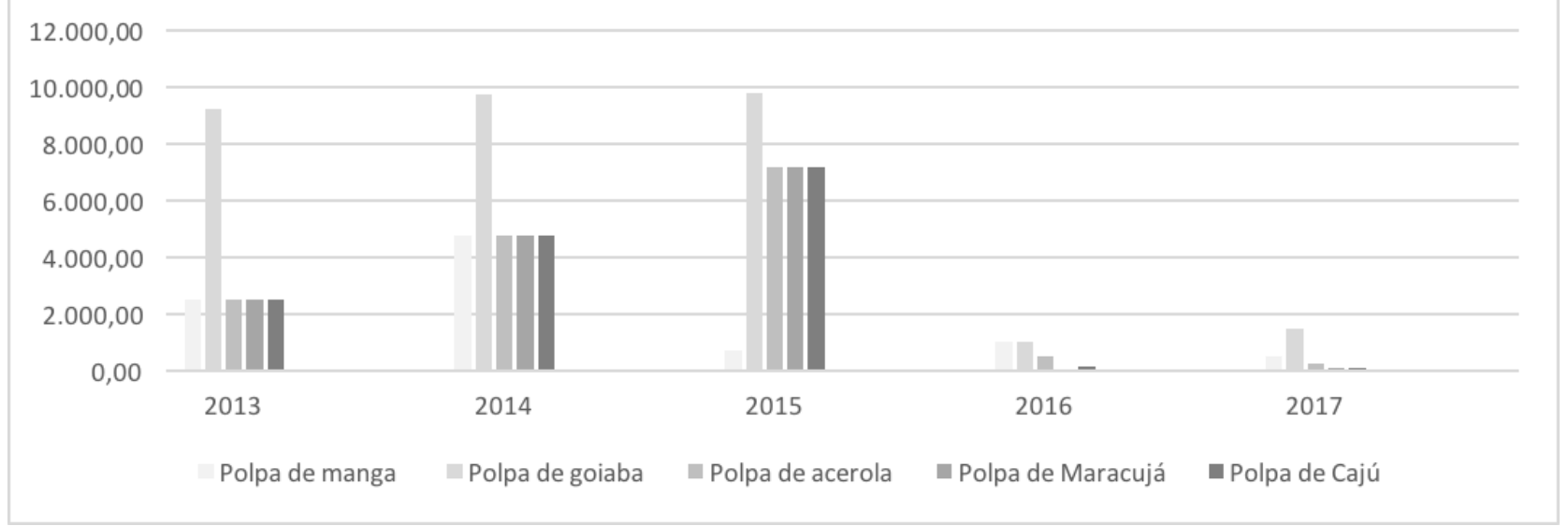

Fonte: Agropecuária Fonte de Sabor (2017).

O valor nominal recebido com a comercialização da produção de polpas de fruta também amentou entre 2013 e 2017 (Gráfico 2). O ano de 2015 marca o auge do processo produtivo e, consequentemente, dos ganhos financeiros. Os entraves para se assegurar o padrão produtivo de 2015, em 2016 e 2017, (em grande medida relacionados ao período de seca que assolou o Semiárido nordestino entre 2012 e 2017) refletiu-se nos valores recebidos e fragilizou o processamento de polpas, porque os compradores da produção, a grande maioria órgãos públicos, acabaram tendo que adquirir os alimentos de outros fornecedores, e uma reinserção dos agricultores familiares da agroindústria no mercado está sendo dificultada. O fortalecimento dos mercados institucionais é necessário para que a agroindústria possa manter sua produção e, consequentemente, a agricultura familiar no assentamento São João II. 
Gráfico 2 - Valor da produção anual de polpa de fruta da agroindústria entre 2013 e 2017

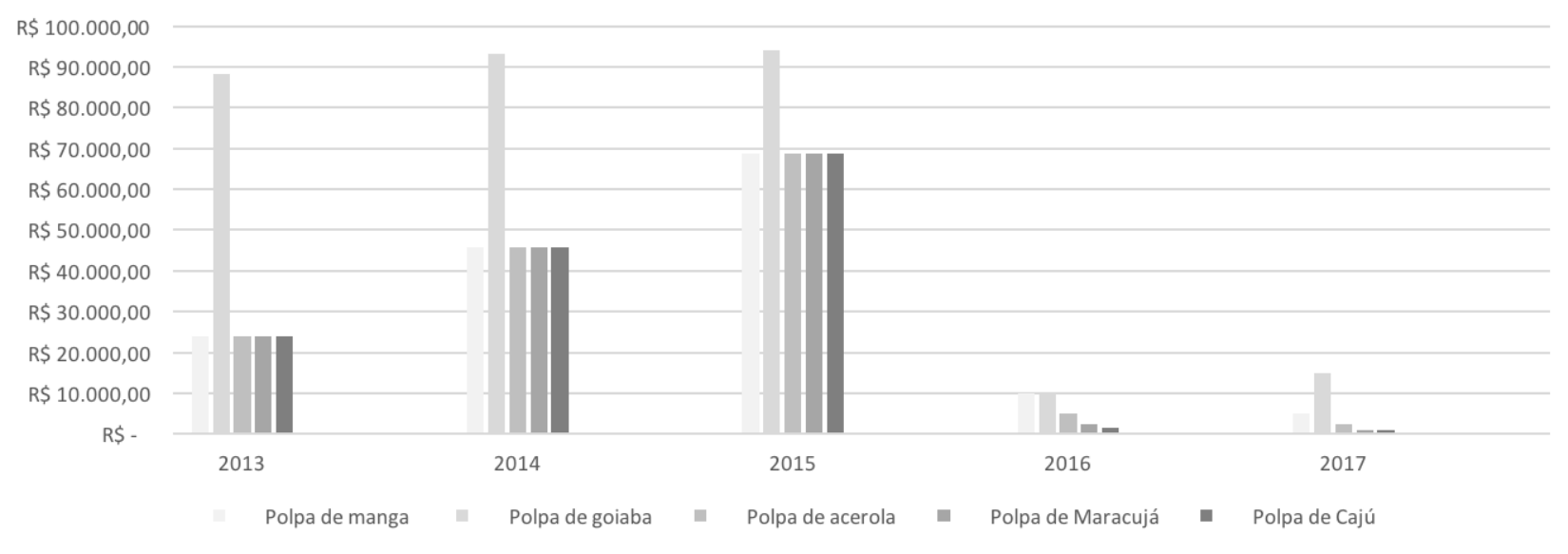

Fonte: Agropecuária Fonte de Sabor (2017).

Para ampliar as possibilidades de comercialização das polpas produzidas, foi criado um manual de identidade visual, um projeto de marketing, em 2016, e um site com as principais informações da Agropecuária Fonte de Sabor, www.fontedesabor.com.br. Deste modo, todas as transformações vivenciadas pelas famílias do assentamento São João II, da passagem de meeiros para agricultores familiares e, depois, para produtores agroindustriais, contribuíram para o fortalecimento e a consolidação da área reformada e, consequentemente, para o pagamento de toda a dívida referente à aquisição da Fazenda São João no ano de 2016.

\section{CONSIDERAÇÕES FINAIS}

As políticas e programas elaborados e implementados para a modernização da agricultura sertaneja nos anos 1970, como o PROTERRA, acabaram contribuindo para a concentração fundiária, porque priorizou a aquisição de terras para médios e grandes produtores. O POLONORDESTE previa a aquisição de terras para desconcentrar a estrutura fundiária, mas alcançou apenas $25,3 \%$ da meta. O PROJETO SERTANEJO, que tinha o objetivo de fortalecer economicamente os estabelecimentos agropecuários, principalmente os pequenos e médios, não produziu os resultados propostos, porque $62 \%$ das operações de crédito beneficiaram produtores com mais de 100 ha (BNB, 1985). Em síntese, esses programas possuíam uma lógica modernizante, pautada no crédito subsidiado e no fortalecimento da estrutura produtiva de medias e grandes propriedades.

O principal impacto das ações que buscaram modernizar a agricultura sertaneja foi a concentração fundiária, porque processo modernizante acabou reforçando a marginalização dos pequenos proprietários e dos trabalhadores rurais sem terra. $\mathrm{O}$ foco das políticas citadas foi o desenvolvimento econômico do Nordeste em detrimento das atividades agropecuárias praticadas pelos pequenos produtores rurais (Ramalho, 1992). Os investimentos em infraestrutura realizados 
foram importantes, mas isoladamente não resolveram os problemas e necessidades de pequenos produtores (Fernandes, 1995).

A virada dos anos 1980 para os anos 1990 marca a mudança - não no modelos das políticas públicas voltadas para o meio rural sertanejo, as quais mantêm a característica de investimentos em infraestrutura para promover o desenvolvimento econômico, por exemplo - dos atores a serem beneficiados. Os pequenos proprietários, agora chamados de agricultores familiares, passam a ter acesso à reforma agrária, a programas de crédito para implementar e custear novas atividades produtivas e ao mercados institucionais que possibilitaram a comercialização da produção. Essa guinada também está relacionada à falência do modelo produtivo que subsidiou os médios e grandes estabelecimentos agropecuários até o fim dos anos 1980.

Não se pode desconsiderar, por outro lado, a atuação de agências internacionais de fomento, como o Banco Mundial, na formulação de políticas públicas direcionadas aos agricultores familiares, por exemplo, a reforma agrária de mercado, que iniciou um processo de reestruturação fundiária que tirou do Estado e atribuiu ao beneficiário os custos de tal processo; o PCPR que financiou a agroindustrialização em assentamentos rurais. Esse conjunto de ações contribuiu para que o assentamento São João II existisse e que as famílias pudessem processar frutas e vender polpas, aumentando, assim, a renda familiar. Contudo o escopo de tais políticas ainda gera entraves à consolidação da agricultura familiar, porque as estratégias modernizantes e de desenvolvimento não contemplam a totalidade do processo produtivo, produção e comercialização, no médio e longo prazo, detendo-se apenas à instalação da estrutura produtiva.

\section{REFERÊNCIAS}

AGROPECUÁRIA FONTE DE SABOR. Programa anual de produção e de vendas. Pombal: Assentamento São João II, 2017. (Relatório Técnico). 2013, 2 p.

ANDRADE, M. C. A terra e o homem no Nordeste. Recife: EDUFPE, 2006, 334 p.

ASSOCIAÇÃO COMUNITÁRIA DO SÃO JOÃO. Sítio São João. Ata da reunião realizada no dia 8 de janeiro de 1995. 1995, Livro 1, p. 1.

ASSOCIAÇÃO COMUNITÁRIA DOS AGROPECUARISTAS DO SÃO JOÃO. Assentamento São João II. Ata da reunião realizada no dia 26 de fevereiro de 2004. 2004, Livro 1, p. 6.

ASSOCIAÇÃO COMUNITÁRIA DOS AGROPECUARISTAS DO SÃO JOÃO. Assentamento São João. Ata da reunião realizada no dia 16 de janeiro de 2005. 2005, Livro 1, p. 9.

ASSOCIAÇÃO COMUNITÁRIA DOS AGROPECUARISTAS DO SÃO JOÃO. Assentamento São João II. Ata da reunião realizada no dia 29 de maio de 2005. 2005, Livro 1, p. 10.

ASSOCIAÇÃO COMUNITÁRIA DOS AGROPECUARISTAS DO SÃO JOÃO. Assentamento São João II. Ata da reunião realizada no dia 19 de agosto de 2007. 2007, Livro 1, p. 15.

ASSOCIAÇÃO COMUNITÁRIA DOS AGROPECUARISTAS DO SÃO JOÃO. Assentamento São João II. Ata da reunião realizada no dia 16 de agosto de 2009. 2009, Livro 1, p. 17. 
ASSOCIAÇÃO COMUNITÁRIA DOS AGROPECUARISTAS DO SÃO JOÃO. Assentamento São João II. Ata da reunião realizada no dia 09 de fevereiro de 2010. 2010, Livro 1, p. 19.

ASSOCIAÇÃO COMUNITÁRIA DOS AGROPECUARISTAS DO SÃO JOÃO. Assentamento São João II. Ata da reunião realizada no dia 23 de julho de 2011. 2011, Livro 1, p. 21.

ASSOCIAÇÃO COMUNITÁRIA DOS AGROPECUARISTAS DO SÃO JOÃO. Assentamento São João II. Ata da reunião realizada no dia 29 de janeiro de 2012. 2012, Livro 1, p. 22.

BNB. Avaliação do POLONORDESTE e do Projeto Sertanejo. Fortaleza: BNB, 1985, 314p.

BRAGAGNOLO, C.; BARROS, G. S. C. Ciclos econômicos na agricultura Brasileira. Revista Brasileira de Economia, Rio de Janeiro, v. 67, n. 2, p. 151-175, 2013.

BRASIL. Ministério do Desenvolvimento Agrário. Programa Nacional de Crédito Fundiário: plano anual de aplicação de recursos - 2003/2004, Brasília, 2003, 101p.

BRASIL. Ministério do Desenvolvimento Agrário. Lei no 11.326, de 24 de julho de 2006. Estabelece as diretrizes para a formulação da Política Nacional da Agricultura Familiar e Empreendimentos Familiares Rurais. Disponível em: <http://www.planalto.gov.br/ccivil_03/_ato20042006/2006/lei/111326.htm>. Acesso em: 11 de março de 2012.

BRASIL. Ministério do Desenvolvimento Agrário. Lei no 11.947, de 16 de junho de 2009. Dispõe sobre o atendimento da alimentação escolar e do Programa Dinheiro Direto na Escola aos alunos da educação básica. Disponível em: <http://www.planalto.gov.br/ccivil_03/_ato20072010/2009/lei/111947.htm>. Acesso em: 11 de março de 2012.

BUAINAIN, A. M. Agricultura familiar e inovação tecnológica no Brasil: características, desafios e obstáculos. Campinas: EDUNICAMP, 2007, 240p.

BUAINAIN, A. M.; SILVEIRA, J. M. F. J.; FONSECA, R. B.; SOUZA FILHO, H. M.; NEDER, H. D.; BUAINAIN, V. P.; BAZIN, F.; PEDROSA, D.; MESQUITA, H.; MELO, M. (2003). Estudo de avaliação de impactos do Programa Cédula da Terra. Campinas. 33p.

CARNEIRO, M. J. Em que consiste o familiar da agricultura familiar? In: COSTA, L. F. C.; FLEXOR, G.; SANTOS, R. Mundo rural brasileiro: ensaios interdisciplinares. Rio de Janeiro: Mauad. 2008, p. 255-269.

CHALOULT, Y. Uma política de legitimação do estado e rearticulação da pequena produção rural. Revista Raízes, Campina Grande, v. 3, n. 4-5, p. 536-548, 1985.

CONSELHO MUNICIPAL DE DESENVOLVIMENTO AGROPECUÁRIO DE POMBAL. Sindicato do Trabalhadores Rurais de Pombal. Ata da reunião realizada no dia 12 de setembro de 2001. 2001, Livro 1, p. 9.

DNOCS. Perímetros irrigados. Disponível em: <http://www.dnocs.gov.br>. Acesso em: 13 mar. 2014.

FERNANDES, M. A. F. A irracionalidade da racionalização: estudo crítico dos conteúdos, práticas e resultados do "GAT" na Paraíba. 123f. Dissertação de Mestrado. Centro de Humanidades, Campina Grande, 1985.

FREIRE, P. Extensão ou Comunicação. 13 ed. Rio de Janeiro: Paz e Terra, 2006, 93p.

GARCIA, E. F. Capacitação sobre boas práticas de fabricação: a força da cooperação transformando vidas no assentamento São João. Pombal: UFCG, 2013. (Relatório Técnico), 2013, $15 \mathrm{p}$.

INCRA. Relação dos projetos de reforma agrária. Disponível em: $<$ http://www.incra.gov.br/reforma_agraria>. Acesso em: 5 ago. 2018. 
GALINDO, E.; RESENDE, G. M.; CASTRO, C.; CRAVO, T. A. Programa Nacional de Crédito Fundiário $(P N C F)$ : uma avaliação de seus impactos regionais. Brasília: IPEA, 2015. Disponível em:

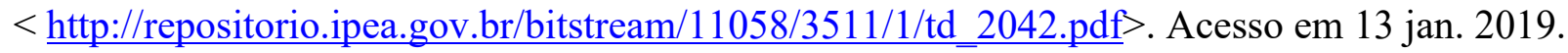

KAGEYAMA, A. A. O novo padrão agrícola brasileiro: do Complexo Rural aos Complexos Agroindustriais". In: DELGADO, G. C. (Org.). Agricultura e políticas públicas. Brasília: IPEA, v. 1, 1990, p. 113-223.

LIMA, J. C. R.; SILVA, M. A. V. A política de assentamentos rurais no contexto de modernização da agricultura brasileira (1950-1990). Geografia em Questão, Cascavel, v. 12, n. 1, 2019, p. 181-195.

MATTEI, L. O papel e a importância da agricultura familiar no desenvolvimento rural brasileiro contemporâneo. Revista Econômica do Nordeste, Fortaleza, v. 45, p. 41-79, dez. 2014.

MIRANDA, R. S.; SILVA, R. B. Uso das áreas de reserva legal e de preservação permanente em assentamentos rurais do Semiárido. Retratos de Assentamentos, Araraquara, v. 20, n. 1, p. 140-163, 2017.

MOREIRA, E.; TARGINO, I. Capítulos de geografia agrária da Paraíba. João Pessoa: EDUFPB, 1997, 280p.

MOURA, J. T. V. Os Conselhos Municipais de Desenvolvimento Rural (CMDRs) e a construção democrática: esfera pública de debate entre agricultores familiares e o Estado. Organizações Rurais \& Agroindústrias, Lavras, v. 9, n. 2, p. 241-255, 2007.

NUNES, E. M.; SCHNEIDER, S. Reestruturação Agrícola, Instituições e Desenvolvimento Rural no Nordeste: A Diversificação da Agricultura Familiar do Polo Açu-Mossoró (RN). Revista Econômica do Nordeste, Fortaleza, v. 44, n. 3, p. 601-626, jul./set. 2013.

NEVES, D. P. Agricultura familiar: quantos ancoradouros! In. FERNANDES, B. M.; MARQUES, M. I. M.; SUZUKI, J. C. Geografia agrária: teoria e poder. São Paulo: Expressão popular, 2007, p. 211-270.

PALMEIRA, M. Modernização, Estado e questão agrária. Estudos Avançados, São Paulo, v. 3, n. 7 , p. 87-108, 1989.

PELEGRINI, G.; GAZOLLA, M. A agroindustrialização como estratégia de reprodução social da agricultura familiar. Estudos Sociedade e Agricultura, Rio de Janeiro, v. 17, n. 2, p. 332-378, 2009.

PICOLOTTO, E. L. Os atores da construção da categoria agricultura familiar no Brasil. Revista de Economia e Sociologia Rural, Brasília, v. 52, n. 1, p. 63-84, 2014.

PIRAUX, M.; MIRANDA, R. S. A longa emergência da agricultura familiar: relações entre atividade agrícola, atores sociais e formas de intervenção do Estado no Agreste paraibano". Revista Raízes, Campina Grande, v. 30, n. 2, p. 52-67, jul./dez. 2010.

PRIORI, A.; POMARI, L. R.; AMÂNCIO, S. M.; IPÓLITO, V. K. A modernização do campo e o êxodo rural. In: PRIORI, A.; POMARI, L. R.; AMÂNCIO, S. M.; IPÓLITO, V. K. História do Paraná: séculos XIX e XX. Maringá: EDUEM, 2012. p. 115-127.

RAMALHO, D. M. S. A pobreza, um problema da sociedade moderna: debate teórico. Cadernos de Ciências Sociais, Recife, n. 3, p. 10-19, 1992.

SAUER, S.; PEREIRA, J. M. M. Capturando a terra: Banco Mundial, políticas fundiárias neoliberais e reforma agrária de mercado. São Paulo: Expressão Popular, 2006, 352p.

SILVA, G. B. e BOTELHO, M. I. V. O processo histórico da modernização da agricultura no Brasil (1960-1979). Campo-Território, Uberlândia, v. 9, n. 17, p. 362-387, 2014.

SILVA, J. G. D. A modernização dolorosa: estrutura agrária, fronteira agrícola e trabalhadores rurais no Brasil. Rio de Janeiro: Zahar, 1992, 192p. 
SILVA, J. G. D.; KAGEYAMA, A. A.; ROMÃO, D. A.; WAGNER NETO, J. A.; PINTO, L. C. G. Tecnologia e campesinato: o caso brasileiro. Revista de Economia Política, São Paulo, v. 3, n. 4, p. 21-56, 1983.

SILVA, M. P. N. S. Assistência técnica e associativismo em assentamentos rurais do INCRA e do Crédito Fundiário. 81f. Monografia de Graduação. Centro de Ciências e Tecnologia Agroalimentar, Pombal, 2009.

SOUSA, J. E. A pecuária leiteira no Estado da Paraíba: um estudo sobre a bacia leiteira de Campina Grande. 156f. Dissertação de Mestrado. Centro de Humanidades, Campina Grande, 1994.

SOUZA, P. M.; LIMA, J. E. Intensidade e dinâmica da modernização agrícola no Brasil e nas unidades da Federação. Revista Brasileira de Economia, Rio de Janeiro, v. 57, n. 2, p. 795-824, 2003.

VICTOR, A. D.; SAUER, S. Estudo sobre a política do Banco Mundial para o setor agrário brasileiro com base no caso do Projeto Cédula da Terra. Brasília: CPT/MST/Rede Brasil/FIANBrasil, 2002.

WESZ JÚNIOR, V. J. Política pública de agroindustrialização na agricultura familiar: uma análise do Pronaf-agroindústria. Revista de Economia e Sociologia Rural, Brasília, v. 48, n. 4, p. 567-596, 2010. 